\title{
THE INNOVATIVE INFRASTRUCTURE OF ECONOMIC DEVELOPMENT IN THE FRAMEWORK OF INTERNATIONAL DIGITAL TRANSFORMATION
}

\author{
Sergii Kolodynskyi ${ }^{1}$, Tetiana Drakokhrust ${ }^{2}$, Maryna Bashynska ${ }^{3}$
}

\begin{abstract}
The development of the innovative digital system, as an important part of the market infrastructure, partly reflects the overall economic level of the country, but its further positive dynamics with the growth of the national economy determines the progress of society as a whole. Methodology. The article provides basis for propositions, aimed at the improvements of development of innovative infrastructure of Ukrainian national economy in the framework of international digital transformation with definition and systematization of all factors that have an impact on the formation of innovation potential and the justification of strategic directions of the development of the infocommunication sphere as a component of the national innovation infrastructure. The development of infocommunication technologies has become an impetus for the formation of the innovation infrastructure of the national economy. The purpose of the article is to study the formation and development of the innovation infrastructure of the digital system in the transitive economy of Ukraine through the reduction of the level of technological development and productivity of production, which requires the stimulation of business entities to innovate. Dependence of the effectiveness of state regulation of the innovation development of infocommunications and the growth of the competitiveness of the national economy is crucial for maximizing the effect of infocommunication thanks to a favourable state policy and an adaptive regulatory framework, taking into account technological changes. Value/originality. The principles of ensuring the development of innovation infrastructure, the effective activity of which guarantees the interaction of subjects and objects of innovation activity, as well as access to various information resources, which, in turn, will increase the efficiency of using the country's innovative potential in the transition period, which is caused by market changes, technological breakthroughs and shifts in the regulatory sphere of Ukraine. The strategic tasks of creating a modern innovation system, including technological and scientific parks, venture funds, technology transfer networks, etc., are grounded. It requires the introduction of mechanisms of public-private partnership in the innovation sphere.
\end{abstract}

Key words: development, digital system, market, innovation infrastructure, information resources, infocommunication technologies, potential, national economy.

JEL Classification: E10, F20, H54, O11, O32

\section{Introduction}

The competitiveness of the national economy is achieved in the current conditions of globalization, based on the strengthening of innovation potential and development, based on information technologies and knowledge that contribute to economic growth. Confirmation is the dependence of a significant part of research and innovation using the technologies of infocommunications and electronic communications that are related to the digital ecosystem of the national economy. The digital ecosystem, which is based on infocommunications,

Corresponding author:

${ }^{1}$ Odessa Academy of Construction and Architecture, Ukraine.

E-mail: kolodi@ukr.net

${ }^{2}$ Ternopil National Economic University, Ukraine.

E-mail: tanya.drakohrust@gmail.com

${ }^{3}$ Odessa Institute of Trade and Economics of Kyiv National University of Trade and Economics, Ukraine.

E-mail: olimpiya@ukr.net gradually combines information technologies, electronic communications, and mass media.

The National Strategy for Sustainable Development "Ukraine 2020" clearly sets itself the task of raising the level of competitiveness of the economy, strengthening the national security of the state, and the development of small and medium-sized businesses and infocommunications are indispensable for this purpose, since the importance of the field of infocommunication is at the crossroads of several national priorities of the economy. In light of the foregoing, the study of 
innovations in the field of infocommunications is gaining weight and needs a strategy of implementation in day-to-day management practices at all levels of the national economy.

The declared measures of the state sustainable development strategy till 2020 envisage ensuring stable dynamics of economic growth on the basis of structural reforms under the vector of the Program for the development of innovations in order to strengthen the institutional capacity of the innovation infrastructure, the main basis of which is the sphere of infocommunications (NCCIR, 2017).

That is why an important issue is the definition and systematization of all factors that have an impact on the formation of innovation potential and the justification of strategic directions of the development of the infocommunication sphere as a component of the national innovation infrastructure.

\section{Analysis of recent researches and publications}

The research questions of the development of digital ecosystems and infocommunications were studied by Martin (2009), which revealed the basis for the formation of a digital ecosystem; Fodor (2008), which substantiates the factors of value creation and value theory in the digital ecosystem; Blijleven, van Angeren, Jansen \& Brinkkemper (2013), which revealed an evolutionary economic approach to the dynamics of ecosystems.

The strategy for the development of the digital ecosystem was considered by Oughton (2018), whose work focuses on policies that should create market conditions and stimulate the emergence of new competitors with innovative thinking; PaulusRohmer, Schatton, \& Bauernhansl (2016) reviewed the directions of adaptation of the strategy after analysing its position in the surrounding ecosystem in terms of informatisation, as well as the relationship of the ecosystem, strategy and business model.

On the other hand, the field of infocommunication is also constantly guided by technological, organizational or business innovation, which is evidenced in the emergence of many new types of electronic services or services. The duality of innovation in the development of infocommunications manifests itself in improving the quality of service provision, on the one hand, and on the other - the development of infrastructure sectors, service sectors, improvement of public administration, and the growth of the competitiveness of the national economy.

It is the last dependence of the effectiveness of state regulation of the innovation development of infocommunications and the growth of the competitiveness of the national economy is crucial for maximizing the effect of infocommunication thanks to a favourable state policy and an adaptive regulatory framework, taking into account technological changes.

The purpose of the article is to study the formation and development of the innovation infrastructure of the digital ecosystem in the transitive economy of Ukraine.

\section{Interpretation and value of development of infocommunications for the economy}

Despite the largely autonomous development of infocommunications as a component of the digital ecosystem, which is determined by market conditions, in order to ensure balanced development, the state must take measures to maintain such a balance and minimize any failures. Government regulation is aimed at developing the field of infocommunication on the basis of, for example, promoting free and fair competition on various technological platforms (neutral regulation), while increasing access to markets and the rapid introduction of innovative services (Bublyk, Koval, \& Redkva, 2017).

In addition to socio-economic development, the maintenance of a widespread innovation infrastructure, which is actively used for the implementation of innovations and contributes to scientific and technological innovation development, is of great importance. According to the legislation of Ukraine, the main element of innovation infrastructure is the subjects of the informational sphere of any form of ownership, which provide infocommunication services for the provision of innovation activities.

The field of infocommunication acts as one of the priority and important areas of the Ukrainian economy, which creates an innovative component in the socioeconomic development of the state, ensuring increased competitiveness of the economy and integration of Ukraine into the global information society, expanding access to national and world information resources (NCCIR, 2017).

That is why an important issue is the definition and systematization of all factors that have an impact on the formation of innovation potential and the justification of strategic directions of the development of the infocommunication sphere as a component of the national innovation infrastructure.

In today's conditions, the tendency of the growing lag of the national economy from the economy of the developed countries of the world to the level of technological development and productivity of production has been formed, including due to the low efficiency of the mechanism of stimulation of business entities to innovate (Oughton, 2018). As a result, there is a significant risk of underdevelopment of innovation infrastructure, which causes a decline in the rate of innovation development, high resource intensity of the national economy, low quality of products and services, and the lack of competitiveness of domestic enterprises (Pukala, Sira, Vavrek, 2018). 
The basisfortheformation ofinnovationinfrastructure, which consists of industrial-technological, financial, infocommunication, and other components (technopolises, technological parks, innovation centres, etc.) (Innovation Index, 2017), was the dynamic development of the sphere of infocommunication, the volume of which in the structure of gross domestic product (GDP) of developed countries can reach up to $7-10 \%$. In Ukraine, GDP produced in the field of infocommunication for 2015 amounted to $3.2 \%$ of Ukraine's GDP, in $2016-3.4 \%$ and in $2017-3.6 \%$ (NCCIR, 2017).

The modern character of the development of the sphere of infocommunication of Ukraine is marked by the growing dynamics of the average annual growth rate of the main segment - the domestic telecommunication market, which was $6.4 \%$ in 2017 , and the growth of the volume of services implemented in the field of informatisation $-24.6 \%$ compared to the previous year (NCCIR, 2017). In the world economy, according to the World Economic Forum, Ukraine has improved its position by some indices and in 2016 took the 64th place, and in January 2015 it was 71.

\section{Approaches to the formation of innovative activity in the conditions of formation and development of digital ecosystems}

The creation and functioning of a single information space, which allows the rapid implementation of innovations by enterprises (production, organizational structure, marketing, etc.), are fundamental to the sustainable development of the field of infocommunications. In the organization of industrial and economic activity of enterprises, the use of infocommunication technologies increases their innovative potential, the assessment of which can be carried out through the costs of infocommunication technologies, which provides an opportunity to identify the influence of the sphere of infocommunication on the main results of the development of the national economy.

It should be noted that in 2012-2015 almost $80 \%$ of the total amount of innovative expenses of the company was directed to the purchase of machines, equipment, and software that characterize the phase of growth of the fifth technological structure, and the average share of enterprises having access to the Internet is $95 \%$ (NCCIR, 2017).

The positive impact of high level of access to the Internet of enterprises and the development of other markets in the field of infocommunications contribute to a structural shift in the economy based on productivity growth and competitiveness, which is especially relevant in the context of globalization. It is the potential contribution of infocommunication technologies as an innovative factor of economic development that shows the greatest effect of growth in their use as the productivity of enterprises in their business model and national economy on the basis of the emergence of new (innovative) products or new markets (sectors). Given the rather comprehensive tendency to spread infocommunication technologies in all areas with low activation of the development of innovation infrastructure, there is no increase in the rates of economic growth, which is due to the need to implement structural and institutional reforms, including in improving the effectiveness of the state policy on the formation and development of innovation infrastructure due to its unsystematic nature, inadequate reasonableness, and the absence of inter-branch and interregional links.

Therefore, it is necessary to strengthen the active position of the state in conducting a policy to create conditions for the development of innovation infrastructure on the basis of mechanisms for the implementation of processes in the field of infocommunications, which will contribute to the formation of an innovative model for the development of the national economy. The low level of development of national innovation infrastructure is found in a small number of developed networks of innovation infrastructure, which produced a reduction in the use of the innovative potential of enterprises in the field of infocommunications.

The products and services in the field of infocommunications serve as the defining characteristics of "service" of innovation activity, and enterprises of the sphere of infocommunication act as subjects of innovation infrastructure, the main purpose of which is to increase innovation activity. Therefore, it is worth considering information technology as an innovative tool that promotes the development of innovations and their commercialization, as well as the formation of innovations in the middle of the field of infocommunication, which influences the development of innovation infrastructure of the national economy within the framework of forming a single information space.

However, today, in comparison with international practices, it is insufficient and requires solving strategic tasks of the development of the field of infocommunications as a component of the innovation infrastructure of the national economy in the following areas (Koval, 2013):

1. Socio-cultural, which, within the framework of the implementation of the national strategy for the further development of the information society in Ukraine, as an innovative society, includes:

- raising the level of computer literacy of the population and introducing and using ICT opportunities in the socio-cultural sphere and other sectors of the economy through the development and implementation of relevant sectoral and cross-sectoral programs; 
- overcoming of digital inequality in the access of Ukrainian citizens to electronic communications and information resources, both "first level" (access of new users) and "second level" (access of existing users), which is related to the social-age gap due to low incomes, especially for certain categories of citizens, and the geographical and cultural gap, which requires the implementation of a compensatory mechanism (subsidies) for operators to connect at affordable prices, taking into account the level of income of the population, etc.

2. Institutional and technological, aimed at creating a coherent legal system concerning:

- obligations (regulatory) for the provision of universal services to the operator of telecommunications with a significant market advantage not only in the area of fixed communications, mobile communication, and broadband Internet access (including through the improvement of the creation of a universal service fund) taking into account the principle of "technological neutrality";

- introduction of mechanisms for the development of the industrial Internet market based on the development of industry standards with the aim of accelerating the harmonization of national legislation with the norms of the legislation of the European Union;

- improvement of the mechanisms of protection of the rights of consumers of telecommunication services in case of termination of the activity of operators, telecommunication providers.

3. Administrative-economic, which within the framework of the creation of national electronic information resources provides:

- reduction of entry barriers due to the burdensome procedures for entering the telecommunications market on the basis of improved licensing in the field of telecommunications;

- improvement of surveillance (control) mechanisms in the field of telecommunications, aimed at preventing violations and reducing potentially possible pressure on business entities;

- strengthening of information security and cyber security based on doctrines and international certificates in the field of information security management;

- development of e-government on the basis of the program on the provision of electronic administrative services.

\section{Transformation of modern business models and strategy of innovative development of the digital ecosystem: international dimension}

It is expedient to formulate the strategy of innovation development of infocommunication on the basis of balanced development of the information society by means of cooperation of the population, business, and the state, which simultaneously promote the creation of a network infrastructure that can increase the bandwidth through the permanent increase of users and intensify the use of their infocommunication services, as well as the expansion and acquisition of digital competencies, necessary for the use of the latest technology that will stimulate the development of the digital economy.

In this regard, the task is to increase the research and innovation activity of participants in the field of infocommunications, taking into account also the needs of other sectors of the national economy.

The largest barriers to the national market for infocommunications on the demand side were low computerization, compared to the world average, as well as the lag in Internet penetration, including the mobile Internet, and the use of online services for most age groups.

The key goal of infocommunication is the use of infocommunications for research, innovation development, and the provision of high-quality electronic services.

However, Ukraine's innovation activity remains at a rather low level and does not correspond to the average level in the European Union. According to the analytical data of national innovation systems and the comparative analysis of the efficiency of innovations in the EU and Ukraine, it can be stated in the classification of countries in four categories (low level of innovation, moderate level of innovation, innovators, and innovation leaders) Ukraine was classified as a low level of innovation with the lowest indicator.

Table 1

Innovation index in the EU and Ukraine

\begin{tabular}{|l|c|c|c|c|}
\hline & $2017 / 2016$ & $2016 / 2015$ & $2015 / 2014$ & $2014 / 2013$ \\
\hline $\begin{array}{l}\text { European } \\
\text { Union }\end{array}$ & $\mathbf{1 0 2 , 0}$ & $\mathbf{1 0 0 , 7}$ & $\mathbf{9 9 , 2}$ & $\mathbf{1 0 0 , 3}$ \\
\hline Belgium & 120,9 & 118,3 & 118,2 & 117,9 \\
\hline Bulgaria & 47,5 & 46,0 & 45,2 & 45,2 \\
\hline $\begin{array}{l}\text { Czech } \\
\text { Republic }\end{array}$ & 84,4 & 85,3 & 83,4 & 85,3 \\
\hline Denmark & 136,7 & 140,1 & 143,5 & 145,6 \\
\hline Germany & 123,4 & 125,0 & 124,5 & 128,9 \\
\hline Estonia & 79,8 & 91,2 & 86,6 & 91,3 \\
\hline Luxembourg & 121,4 & 124,8 & 124,8 & 129,9 \\
\hline Finland & 130,9 & 130,8 & 130,1 & 133,9 \\
\hline Sweden & 143,6 & 142,6 & 141,5 & 145,1 \\
\hline UK & 125,3 & 118,1 & 115,5 & 112,8 \\
\hline Iceland & 121,7 & 124,5 & 126,1 & 126,2 \\
\hline Norway & 115,8 & 101,1 & 100,0 & 102,2 \\
\hline Serbia & 64,2 & 62,8 & 62,2 & 60,7 \\
\hline Switzerland & 164,6 & 161,8 & 158,3 & 158,1 \\
\hline Ukraine & $\mathbf{2 8 , 9}$ & $\mathbf{3 1 , 3}$ & $\mathbf{3 2 , 2}$ & $\mathbf{3 1 , 1}$ \\
\hline Turkey & 59,7 & 60,9 & 59,3 & 46,9 \\
\hline
\end{tabular}

Source: European Innovation Scoreboard 2017. Access Mode: http://ec.europa.eu/ 
One of the sub-indicators of the innovation index is activities in the field of infocommunications, which provide services directly to consumers and contribute to the innovation activities of other firms and in general sectors of the economy. According to this indicator, Ukraine has positive values that are close to the average level in the EU countries.

Table 2

Sub Indicators of the Innovation Index of the EU and Ukraine in 2017

\begin{tabular}{|c|c|c|}
\hline Competencies & EU & Ukraine \\
\hline \multicolumn{3}{|c|}{ Innovative environment } \\
\hline 1.3.1 Broadband access & 13,0 & 11 \\
\hline 1.3.2. Business opportunities & 3,1 & $\mathrm{n} / \mathrm{a}$ \\
\hline \multicolumn{3}{|c|}{ Economic effects } \\
\hline $\begin{array}{l}\text { 4.2.1 Export of medium and } \\
\text { high-tech goods }\end{array}$ & 56,2 & 28,3 \\
\hline $\begin{array}{l}\text { 4.2.2 Export of services } \\
\text { requiring knowledge }\end{array}$ & 69,3 & 51,0 \\
\hline $\begin{array}{l}\text { 4.2.3. Sales of the latest market } \\
\text { and latest innovations }\end{array}$ & 13,37 & 3,30 \\
\hline
\end{tabular}

Source: European Innovation Scoreboard 2017. Access Mode: http://ec.europa.eu/

The above data shows the factors that influence the aggregate indicator of innovation development, where the sub-indicators of exports of services requiring knowledge, as well as the business of innovative products, are a positive trend.

However, when analysing the noted results, it is advisable to substantiate the duality of their origin, since in Ukraine mainly foreign companies are integrated which are integrated into international trade as a part of innovation networks and are weakly related to the national innovation system, while businesses are characterized by a rather low efficiency and innovations.

For this purpose, we will conduct a SWOT-analysis of innovative development of infocommunications.

Table 3

SWOT-analysis of innovation development of the sphere of infocommunications

\begin{tabular}{|c|c|}
\hline Strengths & Weakness \\
\hline $\begin{array}{l}\text { Significant demand for } \\
\text { innovative ICT-based products. } \\
\text { High level of broadband access. }\end{array}$ & $\begin{array}{l}\text { Low participation in } \\
\text { international research projects. } \\
\text { Low culture of cooperation. } \\
\text { A small number of IT clusters. }\end{array}$ \\
\hline Opportunities & Threats \\
\hline $\begin{array}{l}\text { High level of export of services } \\
\text { requiring knowledge. } \\
\text { The ability of ICT enterprises } \\
\text { to attract venture capital }\end{array}$ & $\begin{array}{l}\text { Low cooperation of innovative } \\
\text { SMEs with international } \\
\text { companies. } \\
\text { Using the Internet in the } \\
\text { countryside } \\
\text { There is no intellectual property } \\
\text { market }\end{array}$ \\
\hline
\end{tabular}

Modern services without limitations become available in the Internet environment, which creates demand for the development of infocommunication infrastructure; which require the creation of opportunities for investment in infocommunication networks, which, in turn, contribute to the further development of innovative services.

Therefore, for the development of innovative activities in the field of infocommunications, the state must provide financial support to small and mediumsized enterprises in order to provide the capital for their development, necessary for innovation. Innovation potential in the field of infocommunication relates to research activities as a key factor in economic growth and increasing the competitiveness of ICT products (Koval, 2013).

The innovative infrastructure of infocommunication, which promotes the development of innovations of ICT actors, promotes the expansion of innovation potential and other sectors, as well as the competitive advantage in the international market.

Taking into account the above mentioned, in our opinion, the key elements of innovation development of the sphere of infocommunication are:

1. State regulation of competition, aimed at stimulating an increase in the number of participants in the innovation activity in the market.

One of the key areas of strategic development of the field of infocommunication is the support and stimulation by the state of competition that will stimulate innovation and investment in new network technologies. Given the low level of competition, there is a risk that existing operators will operate with a relatively small number of innovations and new investments in their own infrastructure.

Therefore, in order to stimulate competition that minimizes the risk of reducing innovation and investment, an attention should be paid to creating an environment in which existing operators are interested in introducing new services and providing access to their infrastructure for new service providers on mutually beneficial terms.

However, the presence of competition is a necessary but not sufficient condition for the strategic development of the field of infocommunication, which promotes a healthy investment climate. In view of this, in our opinion, it would be advisable to take measures to promote competition in the provision of access to convergence networks and services in relation to:

- amendments to the current legislation on telecommunications with the establishment of a sectoral legal framework to stimulate and control competition in the field of infocommunications;

- reorganization of the regulator's policy in the field of infocommunication in accordance with the principles and policies embodied in the Directives of the European Union; 
- minimizing the political component of decision-making by the regulator in the field of infocommunications that is based not on political or other forms of compromise between interest groups but on the appropriate qualifications of managers, requiring their development of competences;

- the pricing of services offered by operators with substantial market gains on a fair and transparent basis.

2. Supporting the scientific and human resources and educational potential and the association of educational institutions for the training of IT professionals and business for R\&D cooperation and help in advancing innovations in the business environment and the creation and development of techno parks in the field of IT.

The achievement of this goal is due to the need to develop a "knowledge triangle": higher education, research and innovation, and most importantly, the interaction between them, which will enhance competitiveness within the global knowledge economy, as growing global competition and the emerging demographic situation in Ukraine through the emigration to developed countries, only increase the dependence of economic growth on innovations, but if Ukraine abandons talented young people as future innovators.

The domestic strategy for the development of the field of infocommunication should be aimed at strengthening the role of higher education institutions as drivers of innovation, as future innovators must acquire the necessary competencies and knowledge to promote innovation.

In addition, the constraining factor is only a small experience in the formation of an entrepreneurial culture, which will depend on the proposal for certain types of innovation, which means that such entrepreneurial culture will promote the value of domestic research and innovation, namely within the "knowledge triangle" and in the future will create jobs and new enterprises The strategic orientation of the "knowledge triangle" involves the integration of universities, research centres, companies on a long-term basis around specific social issues with common strategic goals.

3. State regulation of the capital market and the development of venture financing to secure equity financing of start-ups at the initial stage of enterprise formation.

Prospects for innovation development depend not only on the state of scientific and human potential but also on the willingness to perceive relevant innovations and their financing. An important role in the implementation of the above elements of innovation development of the field of infocommunication is to state support, which is aimed at coordinating projects of research work on the creation of innovative products.

As a result of state policy measures aimed at the development of innovative development of the field of infocommunication, the investment activity of both existing and new participants in the market will be intensified. This requires a significant improvement in the conditions for the creation of start-ups, the expansion of financial support for innovative projects at an early stage, including and at the expense of venture capital investment.

Extension of innovation support tools is especially important for small and medium-sized enterprises through co-financing of enterprise costs, for example, for the registration of intellectual property rights, and most importantly, more flexible procedures for obtaining them.

4. Improving the legislative framework in the field of telecommunications and information.

Since the current requirements of the Law of Ukraine "On Telecommunications" need to be changed through the harmonization of rules for investment in infrastructure, for example, through foreseeable conditions or licensing. Integration of EU recommendations into national legislation should help minimize the timing of the procedure, streamline licensing conditions. In addition, modern policy and regulatory framework should be aimed at the creation of e-business (e-commerce) and the consumer environment to promote the growth and growth of infocommunications, as well as to ensure the protection of consumers' interests.

5. Expansion of infocommunication infrastructure on the basis of the interconnection of various broadband networks and digital platforms.

Areas of development of the innovation infrastructure of the national economy:

1. Stable financing conditions with the improvement of financial support mechanisms for innovative projects, including:

- creation of an ICT (sectoral) fund of direct investment in innovative projects of the field of infocommunications with the participation of the State Innovation Finance and Credit Institution for enhancing intra-sectoral coordination and risk sharing with co-financing of projects;

- an increase in the share of expenditures from the State Budget to provide preferential lending for the implementation of innovative projects, especially hightech subjects in the field of infocommunications.

2. Institutional provision of development of innovation activity of subjects of the sphere of infocommunication, which includes:

- stable regulatory environment and compliance of the current legislation (educational, budget) with progressive requirements for commercialization of developments and dynamics of innovative development of subjects of the sphere of infocommunications; - improvement of mechanisms of legal protection of intellectual property in Ukraine with harmonization with the legislation of the European Union. 
3. Improvement of mechanisms of support of innovative projects in foreign markets.

4. Development of innovation activity at the regional level, which includes:

- promotion of intellectual specialization in the regions; - development of regional programs and strategies for innovation development involving private investment and at the expense of the budget for development of local budgets;

- development of broadband infrastructure in rural areas.

In our opinion, the strategic tasks of creating a modern innovation system, including technological and scientific parks, venture funds, technology transfer networks, etc., will require the introduction of mechanisms of public-private partnership in the innovation sector and should be aimed at legislative setting stimulating features for new productions and a start-up in the field of infocommunications (Pukala, Sira, Vavrek, 2018). For example, through the introduction of effective incentives for the development of the field of infocommunications and enhancement of its competitiveness on the world market with a view to the transition to an innovative way of development of the country and ensuring the transformation of the state innovation policy by accelerating the introduction of infocommunication technologies and the development of national information resources.

\section{Conclusions}

The analysis makes it possible to note that solving strategic tasks of the development of the sphere of infocommunications is central to the development of the country's innovation infrastructure. Since research and innovation are possible through the use of infocommunication and electronic communications technologies that relate to the digital ecosystem of the national economy based on infocommunications, it gradually combines information technology, electronic communications, and mass media. The need for the development of the field of infocommunication is one of the priorities in ensuring the development of innovative infrastructure, the effective operation of which guarantees the interaction of subjects and objects of innovation activity, as well as access to various information resources, which, in turn, will increase the efficiency of the use of innovative potential countries. Functioning of the field of infocommunications and innovative processes that support it takes place in a transitional period, which is caused by market changes, technological breakthroughs and shifts in the regulatory sphere of Ukraine. Promising for innovative development of the sphere of infocommunication are: regulation of competition, aimed at stimulating an increase in the number of participants in the innovation activity in the market; support of the scientificpersonnel and educational potential and the association of educational institutions for the training of IT specialists and business; regulation of the capital market and development of venture financing; improving the legislative framework in the field of telecommunications and information; expansion of infocommunication infrastructure on the basis of the interconnection of various broadband networks and digital platforms.

It is proposed to strengthen the active position of the state in conducting a policy to create conditions for the development of innovation infrastructure on the basis of mechanisms for implementation of processes in the field of infocommunications, which will contribute to the formation of an innovative model for the development of the national economy.

\section{References:}

Blijleven, Vincent \& van Angeren, Joey \& Jansen, Slinger \& Brinkkemper, Sjaak (2013). An evolutionary economics approach to ecosystem dynamics. 19-24. doi: 10.1109/DEST.2013.6611323.

Bublyk, M., Koval, V., Redkva, O. (2017). Analysis impact of the structural competition preconditions for ensuring economic security of the machine building complex. Marketing and Management of Innovations, vol. 4, $229-240$. doi: $10.21272 / \mathrm{mmi} .2017 .4-20$.

Fodor, George. (2008). The Value of Information as a Theoretical Foundation for Digital Ecosystems. 26-29. doi: 10.1109/DEST.2008.4635097.

Innovation Index (2017). Web Index. Retrieved from: http://thewebindex.org/data

Koval, V. (2013). Integration processes in the telecommunication sector in Europe. Současná Evropa, 2, $129-141$.

Martin, Florin (2009). The digital ecosystem related with the development of SMEs. 16th International Economic Conference - IECS 2009, 129-132.

NCCIR (2017). Annual report in 2017. Retrieved from: http://www.nkrzi.gov.ua

Oughton, Edward. (2018). The strategic national infrastructure assessment of digital communications. doi: 10.17863/CAM.23343.

Paulus-Rohmer, Dominik \& Schatton, Heike \& Bauernhansl, Thomas. (2016). Ecosystems, Strategy and Business Models in the age of Digitization - How the Manufacturing Industry is Going to Change its Logic. Procedia CIRP, 57, 8-13. doi: 10.1016/j.procir.2016.11.003.

Pukala, R., Sira, E., Vavrek, R. (2018). Risk management and financing among start-ups. Marketing and Management of Innovations, 3, 153-161. 